\title{
Covalently-Linked Polyoxometalate-Polypyrrole
}

\section{Hybrids: Electropolymer Materials with Dual Mode \\ Enhanced Capacitive Energy Storage}

Sarah A. Alshehri ${ }^{a, b}$, Ahmed Al-Yasari ${ }^{a, c *}$, Frank Marken $^{d}$, John Fielden ${ }^{a *}$

${ }^{a}$ School of Chemistry, University of East Anglia, Norwich, NR4 7TJ, United Kingdom.

${ }^{\mathrm{b}}$ School of Chemistry, Princess Nourah bint Abdulrahman University, Riyadh, Saudi Arabia.

${ }^{\mathrm{c}}$ Department of Chemistry, Faculty of Science, University of Kerbala, Kerbala, Iraq.

${ }^{\mathrm{d}}$ School of chemistry, University of Bath, Bath, BA2 7AY, United Kingdom.

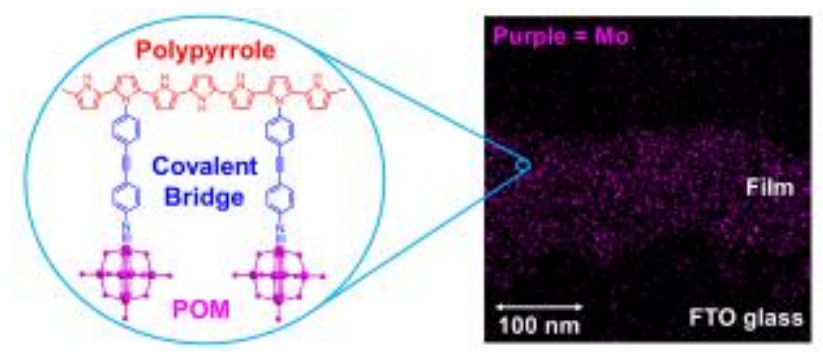

KEYWORDS: Polyoxometalates, Polypyrroles, Hybrid materials, Supercapacitive, Energy storage.

ABSTRACT: Lindqvist-type polyoxometalates (POMs) derivatised with pyrrole (Py) via an arylimido linkage $\left[\mathrm{Mo}_{6} \mathrm{O}_{18} \mathrm{NPhPy}\right]^{2-}$ (1) and $\left[\mathrm{Mo}_{6} \mathrm{O}_{18} \mathrm{NPhCCPhPy}^{2-}\right.$ (2) undergo co- 
electropolymerisation with pyrrole, producing the first electropolymer films with covalently attached POM "molecular metal oxides". XPS and EDX elemental analysis indicate that the loadings of POM achieved are far higher than in conventional, non-covalent inclusion films, and covalent attachment prevents loss of POM on initial reduction cycles. Cyclic voltammetry, electrochemical impedance spectroscopy and galvanostatic charge discharge measurements together indicate that the POMs enhance the specific capacitance (up to $5 \times$ ), and decrease the charge transfer resistance of the films by both modifying the behavior of the polypyrrole (PPy) film, and introducing a substantial additional faradaic contribution through the POM redox processes. Increasing the length of the POM-PPy linker improves both capacitance, and stability, with PPy-2 retaining 95\% of its initial capacitance over 1200 cycles.

\section{Introduction}

Polyoxometalates, a vast class of anionic, molecular metal oxides,,${ }^{1,2}$ offer a wealth of catalytic ${ }^{3-5}$, magnetic ${ }^{6,7}$ and electro-optical ${ }^{7-10}$ properties suitable for exploitation in materials. Amongst the most important are their ability to act as stable, multi-electron acceptors (up to 24 electrons in the solid state ${ }^{11}$ ) with structures and properties that can be tailored for specific demands on the molecular level - for example by connection of organic moieties ${ }^{12-15}$ or inclusion of almost any heterometal. ${ }^{16}$ Coupled with their facility for rapid electron transfer, this makes them an excellent basis for electrochemical energy storage in batteries and supercapacitors, ${ }^{17-20}$ as demonstrated by use of $\left[\mathrm{PMo}_{12} \mathrm{O}_{40}\right]^{3-}$ and $\left[\mathrm{PW}_{12} \mathrm{O}_{40}\right]^{3-}$ as cathode materials for lithium ion batteries. ${ }^{20}$ However, the direct use of POMs in both these and other devices is restricted by high solubility and low conductivity as they are typically salts with negligible conductivity. ${ }^{21}$

Interfacing POMs with devices can be achieved by electrically "wiring" the POM to conductive substrates, such as conductive polymers (CPs). These are an attractive choice as their electronic 
and optical properties, including charge storage, ${ }^{22,23}$ can complement those of the POM and there is a growing interest in composite materials that introduce other functional components (metal oxides, metal nanoparticles) to CPs, resulting in enhanced, emergent properties. ${ }^{24-26}$ Polypyrrole (PPy) is the most widely studied $\mathrm{CP}$ due to its combination of facile synthesis and device construction by electropolymerisation, with high electrical conductivity, high energy storage capacity, high stability and biocompatibility. ${ }^{27}$ POMs have been incorporated into PPy by noncovalent inclusion in the cationic PPy matrix, producing materials with enhanced properties for energy storage, ${ }^{28-30}$ and catalysis and sensing applications. ${ }^{31-34}$ However, POM loadings are restricted by the level of positive charge on the PPy and the anions can be vulnerable to leaching, particularly upon redox cycling. Loading and stability could be increased by covalent linkage, ${ }^{12}$ and the increased control over spatial relationships and electronic coupling provided by covalent materials is expected to provide enhanced and novel properties. In supercapacitors specifically, performance may be enhanced by covalently "wiring" charge storage components together at the molecular level so as to maximize the electron-transfer activity within the material and to the external circuit. Yet, there are relatively few prior examples of POMs covalently connected to polymers, ${ }^{12,35-37}$ and to our knowledge none involving PPy or other common CPs (e.g. polythiophenes, polyaniline) that can be grown by electropolymerization.

Thus, motivated by the general desirability of a covalent route to POM-PPy hybrids, and recent reports indicating the enhanced capacitive energy storage of PPy non-covalently doped with Lindqvist $\left(\mathrm{M}_{6} \mathrm{O}_{19}{ }^{\mathrm{n}-}\right)$ polyoxometalate anions, ${ }^{38}$ we report the synthesis of PPy covalently linked to arylimido-Lindqvist anions $\left[\mathrm{Mo}_{6} \mathrm{O}_{18} \mathrm{NAr}\right]^{2-}$ through co-electropolymerisation of pyrrole with POM functionalized monomers (Scheme 1). Study of the resulting films by DC and AC electrochemical techniques, electron microscopy, XPS and EDX indicates stable films with very high POM 
loadings, and increases in specific capacitance of up to $5 \times$ vs underivatised PPy that are influenced by the length of the POM-pyrrole bridge. These arise both from the direct faradaic contribution of the POM electron acceptor, and improved performance of the PPy itself that can be attributed to the steric bulk of the POM and bridge forcing a more open, porous packing of the PPy chains.

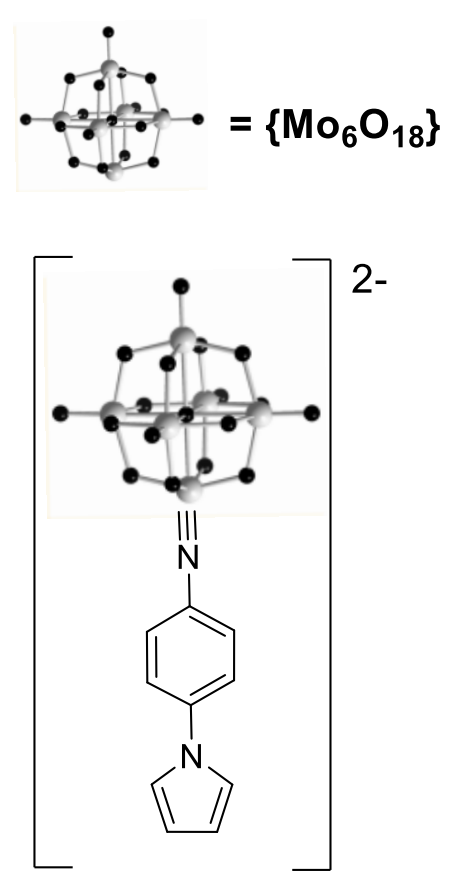

Monomer 1

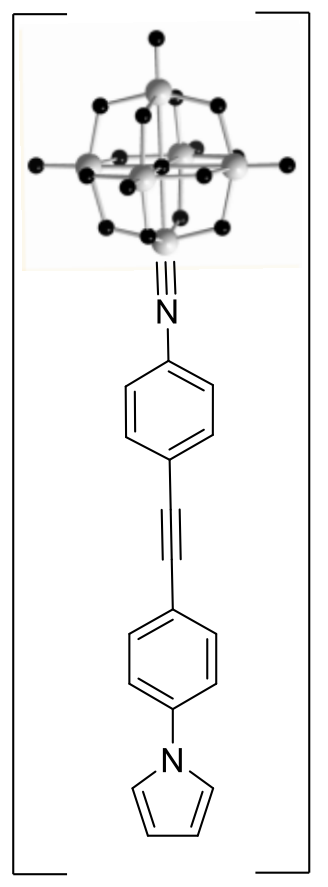

Monomer 2

Scheme 1. Organoimido-hexamolybdate anion-based monomers 1 and 2.

\section{Experimental Section}

All chemicals were purchased from Sigma Aldrich (Gillingham, UK). Acetonitrile solvent was dried by reflux over $\mathrm{CaH}_{2}$ and collected by distillation. Tetrabutylammonium tetrafluoroborate $\mathrm{Bu}_{4} \mathrm{NBF}_{4}$ was prepared following a literature method ${ }^{39}$ and used for all experiments as electrolyte. Monomers $1\left(\left[\mathrm{NBu}_{4}\right]_{2}\left[\mathrm{Mo}_{6} \mathrm{O}_{18} \mathrm{NC}_{6} \mathrm{H}_{4} \mathrm{NC}_{4} \mathrm{H}_{4}\right]\right)$ and $2\left(\left[\mathrm{NBu}_{4}\right]_{2}\left[\mathrm{Mo}_{6} \mathrm{O}_{18} \mathrm{NC}_{6} \mathrm{H}_{4} \mathrm{CCC}_{6} \mathrm{H}_{4} \mathrm{NC}_{4} \mathrm{H}_{4}\right]\right)$ were synthesised by procedures previously developed and published by our group. ${ }^{40}$ 
All electrochemical experiments were performed under nitrogen by using a Schlenk line or glove box and performed using the Autolab PGSTAT302N potentiostat/galvanostat module (Metrohm) with three electrode system. The glassy carbon (GC) working electrode was polished using polycrystalline Diamond suspension $3 \mu \mathrm{m}$ and $1 \mu \mathrm{m}$ respectively and then alumina $0.3 \mu \mathrm{m}$. The counter electrode was $\mathrm{Pt}$ and $\mathrm{Ag}$ or $\mathrm{Ag} / \mathrm{AgCl}$ were used as a reference electrode, where the ferrocene (II/III) couple $\left(\mathrm{Fc} / \mathrm{Fc}^{+}\right)$is at $0.43 \mathrm{~V}$ versus $\mathrm{Ag} / \mathrm{AgCl}$. Cyclic voltammetry experiments were performed using three compartments cell. Electrodeposition experiments were performed by cyclic voltammetry at potential range from -0.2 to $1.8 \mathrm{~V}$, using glassy carbon (GC), fluorine tin oxide (FTO) glass and Pt electrodes immersed in dry acetonitrile with $0.1 \mathrm{M} \mathrm{Bu}_{4} \mathrm{NBF}_{4}$ electrolyte, $7 \times 10^{-4} \mathrm{M}$ POM derivative monomer $\mathbf{1}$ or $\mathbf{2}$, and $3 \times 10^{-4} \mathrm{M}$ pyrrole.

Electrochemical impedance spectroscopy (EIS) measurements were carried out using -0.9 to $1.5 \mathrm{~V}$ potentials at current range $1 \mathrm{~mA}$ with a frequency range from 10 to $10^{6} \mathrm{~Hz}$, to evaluate the charge transfer resistance and electrolyte diffusion of 10 deposition-cycles co-polymer films on GC electrodes. The electrolyte was dry acetonitrile with $0.1 \mathrm{M} \mathrm{Bu}_{4} \mathrm{NBF}_{4}$, reference electrode $\mathrm{Ag}$ wire.

Galvanostatic charge-discharge experiments were performed on GC electrodes coated with 10 deposition cycle films of PPy, PPy-1 and PPy-2, using a potential range of 2 to $-2 \mathrm{~V}$ against an Ag wire pseudo reference electrode. The electrolyte was $0.1 \mathrm{M} \mathrm{Bu}_{4} \mathrm{NBF}_{4}$ in dry acetonitrile.

EQCM measurements used a carbon-coated $6 \mathrm{MHz}$ quartz AT-cut crystal electrode $(\varnothing=6.0 \mathrm{~mm})$ immersed in dry acetonitrile with $0.1 \mathrm{M} \mathrm{Bu}_{4} \mathrm{NBF}_{4}$ electrolyte, and $7 \times 10^{-4} \mathrm{M}$ POM derivative monomer $\mathbf{1}$ or $\mathbf{2}$, and $3 \times 10^{-4} \mathrm{M}$ pyrrole. 
SEM and TEM measurements were performed using high-resolution TEM at the Leeds EPSRC National Nanoscience Facility (LENNF). Sample preparation involved the use of FEI Nova200 dual beam SEM/FIB fitted with a Kleindiek micromanipulator and operated at $30 \mathrm{keV}$ (5 keV for final cleaning) with beam currents between 5 and $0.1 \mathrm{nA}$, technique for cross-section TEM (for both film thickness determination and bulk morphological studies). By taking advantage of the combination of FIB with an SEM, it was possible to have high-resolution images for the surface of the polymer films. SEM images and EDX analysis were also measured at UEA using Philips CM200 FEGTEM fitted with a Gatan SC200 Orius CCD camera and an Oxford Instruments 80 mm2 EDX SDD running AZtec software.

\section{Results and Discussion}

\section{Cyclic Voltammetry of Monomers and their Electropolymerization into Films}

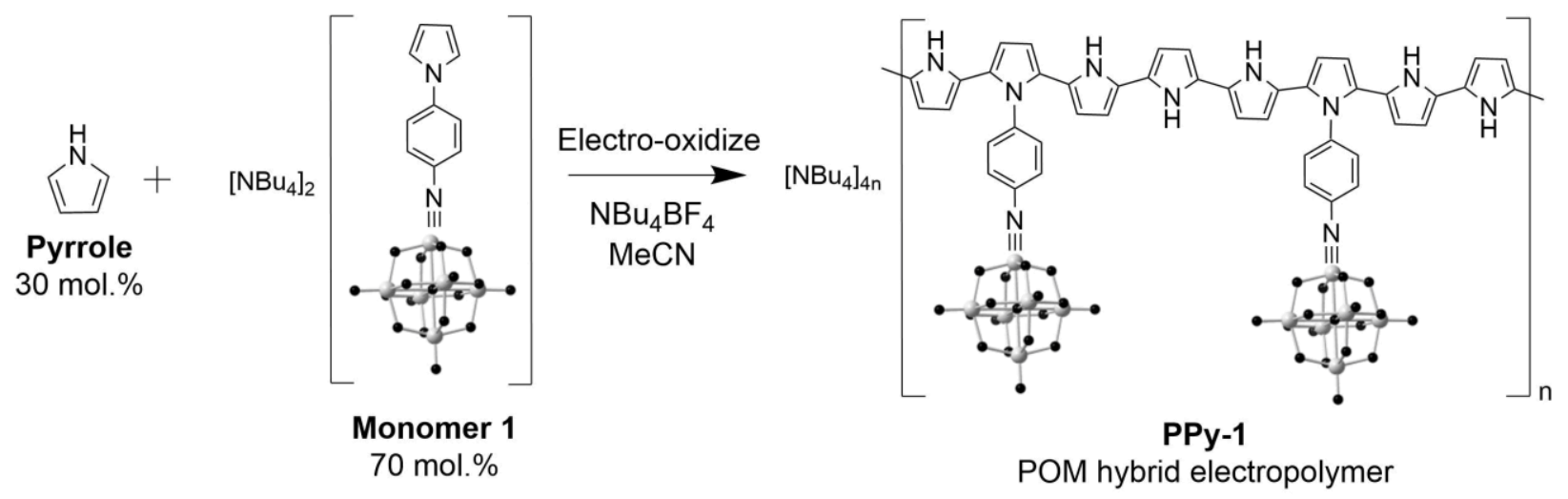

Scheme 2. Electropolymerization of monomer 1 to form PPy-1. The polypyrrole is shown in its reduced state with a monomer 1:pyrrole ratio approximately consistent with EDX, XPS and electrochemical measurements. PPy-2 is synthesized by an identical procedure with monomer $\mathbf{2}$. 

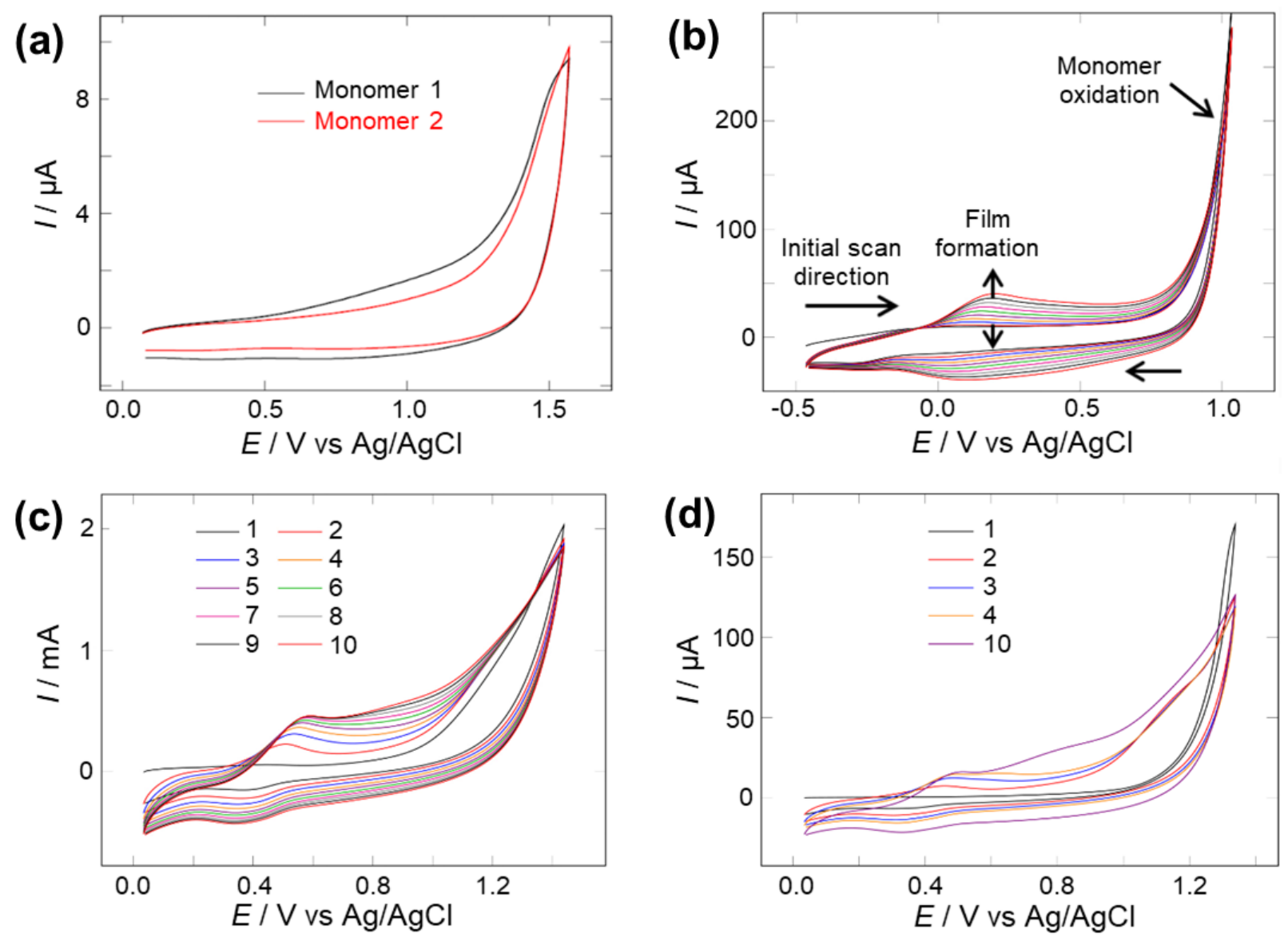

Figure 1. CVs of: (a) Oxidation of monomer 1 (black trace) and monomer 2 (red trace) using glassy carbon (GC); (b) Formation of PPy by electropolymerisation on Pt surface; (c) Coelectropolymerization of monomer 1 70:30 pyrrole on FTO to form PPy-1; (d) Coelectropolymerization of monomer 2 70:30 pyrrole to form PPy-2 on FTO. All experiments were performed in $0.1 \mathrm{M} \mathrm{NBu}_{4} \mathrm{BF}_{4}$ in $\mathrm{MeCN}$ with an aqueous $\mathrm{Ag} / \mathrm{AgCl}$ reference electrode, at a scan rate of $100 \mathrm{mV} / \mathrm{s}$.

Electropolymerisation of pyrrole permits the direct deposition of thin, well-adhered, and highly conductive polymer films onto electrode surfaces. Cyclic voltammetry (CV) studies were carried out to investigate the ability of monomers $\mathbf{1}$ and $\mathbf{2}$ (as tetrabutylammonium salts) to polymerise and produce polymer films with covalently incorporated $\left\{\mathrm{Mo}_{6}\right\}$ units, and to indicate the behaviour 
of the $\left\{\mathrm{Mo}_{6}\right\}$ units which are well known as highly reversible single electron acceptors. CV shows similar behaviour for monomers $\mathbf{1}$ and $\mathbf{2}$ to $\left[\mathrm{Mo}_{6} \mathrm{O}_{19}\right]^{2-}$ in a reductive sweep,,${ }^{9,40}$ but with a negative shift in potential of $c a .180 \mathrm{mV}$ introduced by the electron-donating organoimido group, to around $-0.5 \mathrm{~V} v s \mathrm{Ag} / \mathrm{AgCl}$ for both (Figure S1). Sweeping these monomers oxidatively to up to $+1.8 \mathrm{~V}$ reveals an irreversible oxidative process peaking at $+1.4 \mathrm{~V}$ associated with the pyrrole units (see Figure 1a), but no sign of electropolymerisation: subsequent oxidations resulted in poor and broad peak currents with no film deposited onto the electrode surface. This is not surprising, as Nsubstituted pyrroles often show a lack of polymerization, due to steric hindrance (presence of the sterically demanding phenyl ring and $\left\{\mathrm{Mo}_{6}\right\}$ cluster), and possibly a weak interaction between the radical cation of the monomer and the negatively charged $\left[\mathrm{Mo}_{6} \mathrm{O}_{18} \mathrm{NAr}\right]^{-2}$ cluster. ${ }^{41-44}$

Co-polymerisation has been shown to be one solution for such problems, where a polymerizable monomer such as pyrrole (see Figure $1 \mathrm{~b}$ ) is mixed with the desired monomer. ${ }^{43,45}$ Thus, we found that the derivative monomers would co-electropolymerize with underivatized pyrrole at up to 70 mol. \% of Monomers 1 and $\mathbf{2}$ to form corresponding co-polymers PPy-1 and PPy-2, respectively, see Figure $1(\mathrm{c}, \mathrm{d})$ and Figure S2. Film formation is indicated by growth of an electrochemical process centred at $c a .0 .5 \mathrm{~V}$ for the POM derivatives PPy-1 and PPy-2, and $c a .0 .2 \mathrm{~V}$ for PPy, which corresponds to oxidation of the polypyrrole backbone deposited at the electrode and the onset of its conductive, capacitive region. The positive shift in this oxidation for the POM derivatives is important, as a change in oxidation potential of the film implies polymer chains that are chemically different to PPy - i.e. possessing a distribution of the derivatized and underivatized pyrrole units. This is further supported by a larger positive shift $(c a+0.4 \mathrm{~V})$ in the peak monomer oxidation potential observed in synthesis of PPy-1 and PPy-2 vs PPy, as they imply the involvement of monomers $\mathbf{1}$ and $\mathbf{2}$ in the polymerisation reactions. It is also consistent with the 
literature, where functionalization of pyrrole, especially at the N-position, may introduce electronic effects that shift the oxidation potential of the monomer. ${ }^{44,46}$

\section{Electrochemical Quartz Crystal Microbalance Study}

Electrochemical quartz crystal spectroscopy (EQCM) is a powerful technique to investigate changes of mass, by the change in frequency during the deposition of the polymeric film. It enables measurement of the mass of the deposited film according to the Sauerbrey equation:

$$
\Delta f=-C_{f} \cdot \frac{\Delta m}{A}
$$

Where $\Delta f$ is the change in frequency $(\mathrm{HZ}), C_{f}$ is the sensitivity factor of the crystal $\left(0.0815 \mathrm{~Hz} \mathrm{ng}^{-}\right.$ ${ }^{1} \mathrm{~cm}^{2}, \Delta m$ is the mass change per unit (ng), and $A$ is the area of the substrate $\left(\mathrm{cm}^{2}\right)$. EQCM was recorded with swept potential during formation of PPy, PPy-1 and PPy-2 in acetonitrile with 0.1 $\mathrm{M} \mathrm{Bu}_{4} \mathrm{NBF}_{4}$ (Figure 2). In all cases, a frequency decrease (Figure $2 \mathrm{~d}, \mathrm{e}, \mathrm{f}$ ) is observed with each cycle in the potential range between -0.2 to $1.6 \mathrm{~V}$, indicating increased mass due to film deposition. Interestingly, it can be seen that while PPy-1 $\left(2.08 \times 10^{-6} \mathrm{~g}\right.$ average per cycle on 0.07 $\left.\mathrm{cm}^{2}\right)$ deposits more mass than PPy $\left(1.04 \times 10^{-6} \mathrm{~g}\right.$ average per cycle), consistent with the high formula weight of monomer 1 , PPy-2 shows less deposited mass $\left(0.86 \times 10^{-6} \mathrm{~g}\right.$ average per cycle $)$ compared to either of the other materials. This is consistent with the increased steric bulk provided by the longer $\pi$-bridge in monomer 2 impeding the polymerisation and deposition process, ${ }^{41-43}$ leading to slower ${ }^{47}$ and thus more ordered ${ }^{48}$ polymer chain growth. 

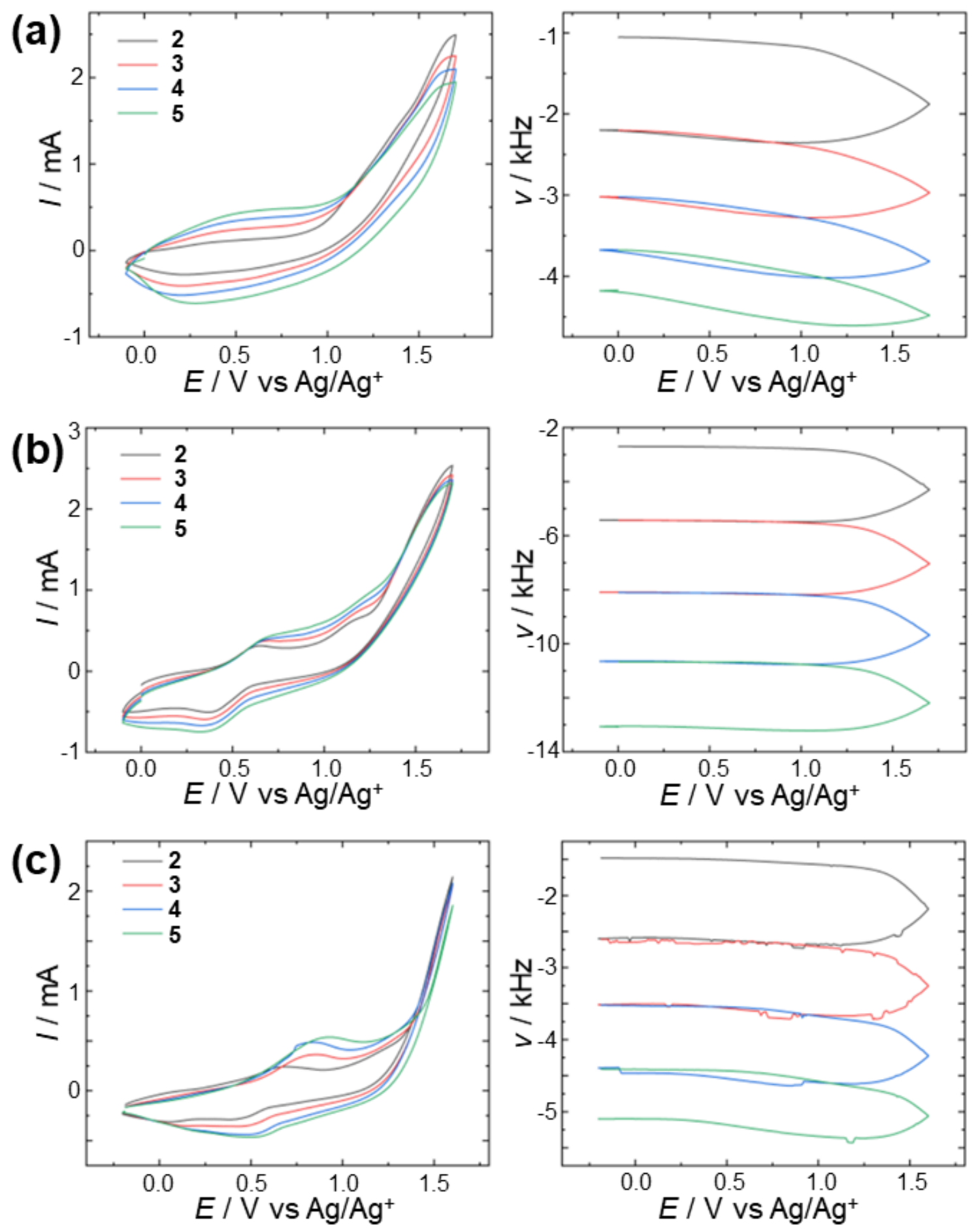

Figure 2. CVs (left) and ECQM frequency changes (right) during formation of: (a) PPy; (b) PPy1; and (c) PPy-2 over a $1.8 \mathrm{~V}$ potential range vs $\mathrm{Ag}$ wire as reference. $0.1 \mathrm{M} \mathrm{Bu}_{4} \mathrm{NBF}_{4}$ in acetonitrile, scan rate $100 \mathrm{mVs}^{-1}$. 


\section{Electron Microscopy}
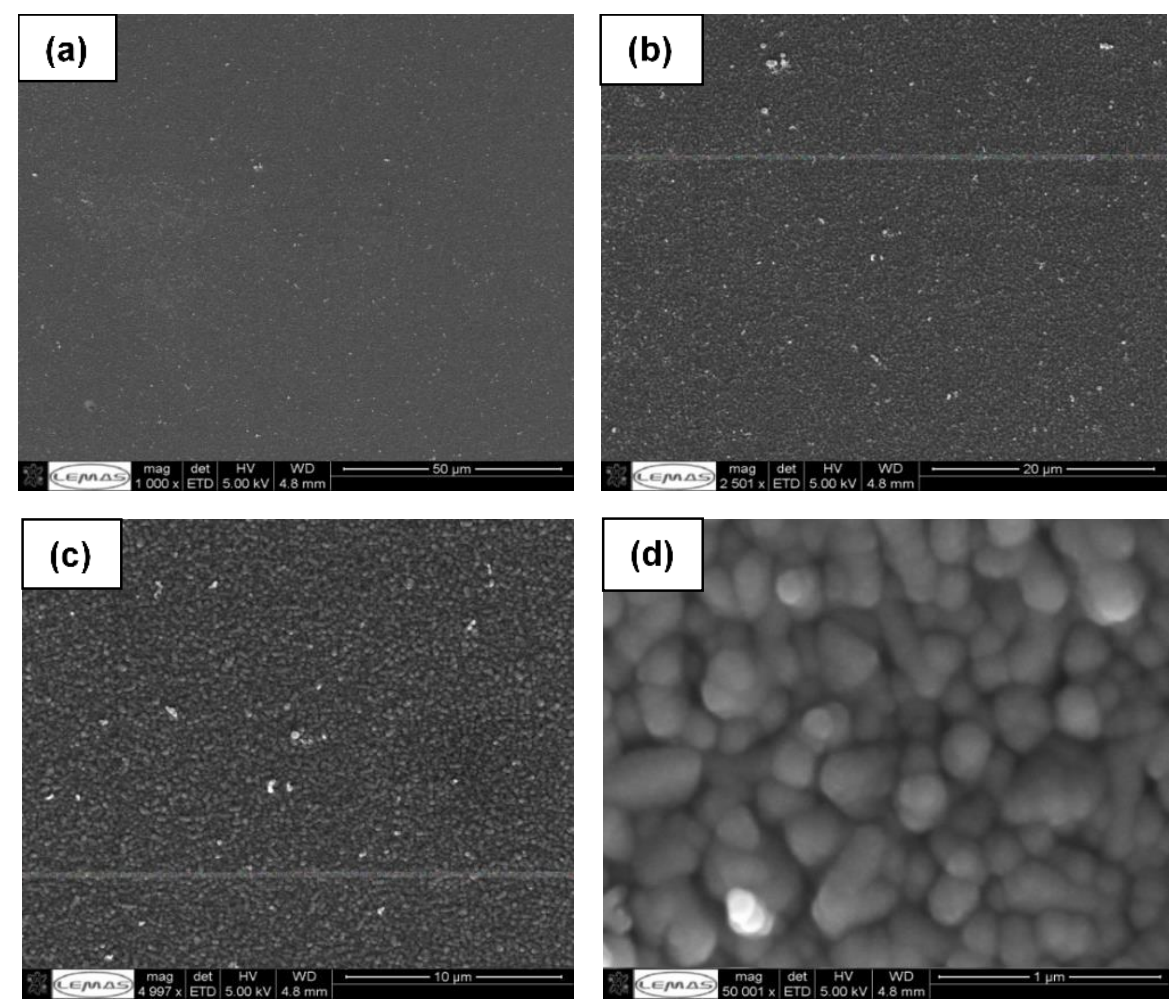

Figure 3. SEM images of the PPy-2 co-polymer, 10 cycles film thickness on FTO electrode at resolutions of (a) $50 \mu \mathrm{m}$, (b) $20 \mu \mathrm{m}$, (c) $10 \mu \mathrm{m}$, (d) $1 \mu \mathrm{m}$.

The surface morphology of the resulting electrogenerated films on FTO glass electrodes, at different film thicknesses were analysed by scanning electron microscopy (SEM) and highresolution transmission electron microscopy (TEM) with cross-section analysis. The morphology of PPy-1 and PPy-2 co-polymers is uneven; however, other N-substituted pyrroles have been found to show more even morphology. ${ }^{49}$ This implies a higher surface area, and thus potentially higher performance for these POM-derivatised materials due to improved charge transport between film and electrolyte. Figure 3 shows the SEM images of PPy-2 of 10 cycles film thickness. In the high-magnification image, the amorphous nature with densely packed surfaces based on spherical particles can be clearly observed, with no phase separated domains. TEM images show 
clearly that the topography of the films is relatively similar to that of the FTO substrate (Figure 4). Film thicknesses were between 60 to $120 \mathrm{~nm}$ depending on the number of deposition cycles, and elemental mapping shows that Mo is present through the entire thickness of the film, confirming that there is no phase separation.
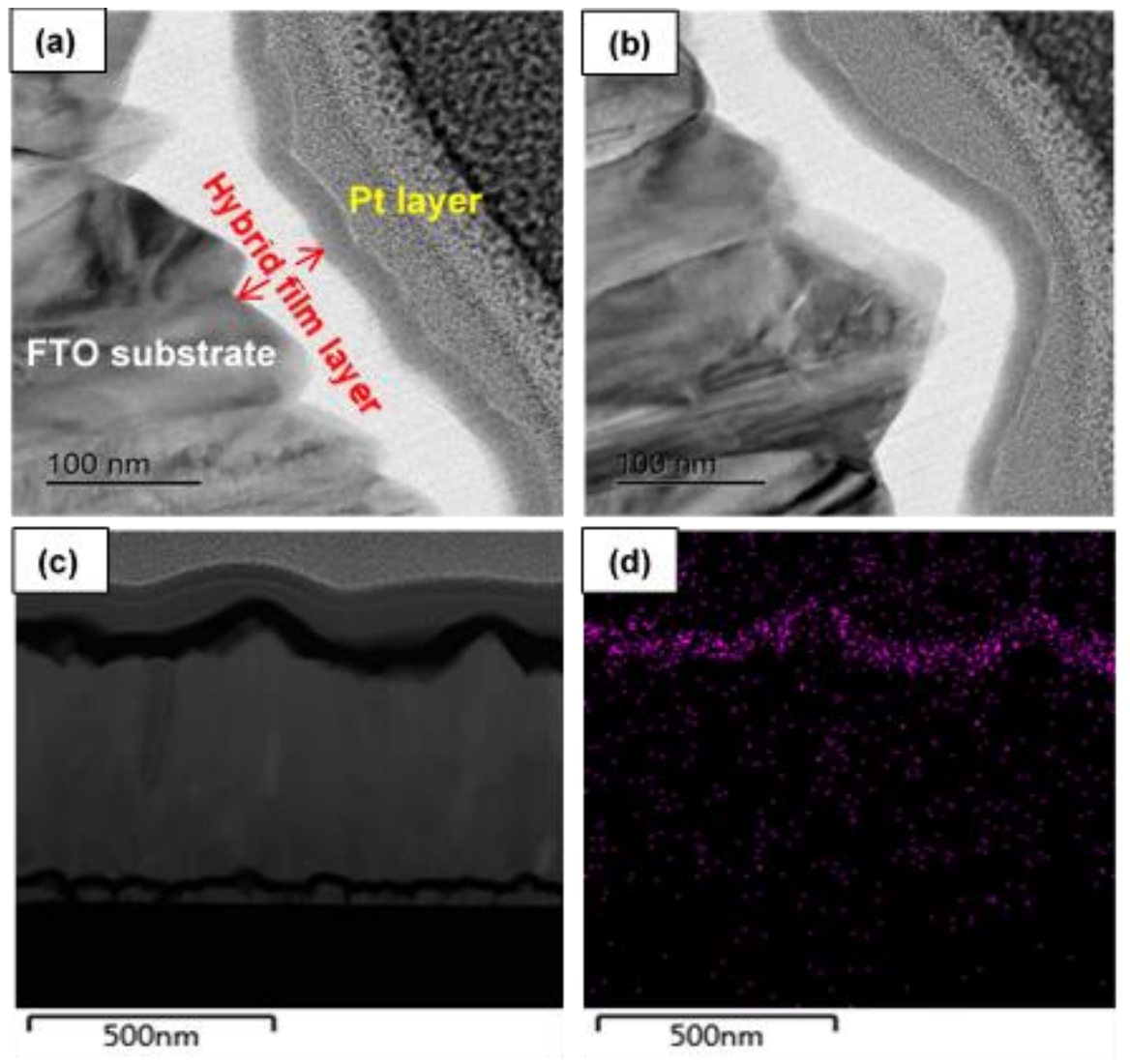

Figure 4. TEM cross-sectional view images of PPy-2, 10 cycles film thickness (60 nm) on FTO electrode at resolutions of (a) $100 \mathrm{~nm}$ showing the layer of the deposited film, (b) $100 \mathrm{~nm}$ showing the topography of the deposited film, (c) at $500 \mathrm{~nm}$ cross-sectional and (d) Mo map (violetcoloured) of the deposited polymeric film.

\section{Reflectance Fourier-transform IR characterization}

The PPy-1 co-polymer was studied by reflectance FT-IR spectroscopy to identify the surface functionalities. Fresh films of the co-polymer were deposited on a Pt working electrode, then 
washed with fresh $\mathrm{MeCN}$ and allowed to air dry with no marking of cracking or peeling. Spectra were measured against the uncoated polished Pt electrode, and the spectra were compared with those for monomer and PPy only films. The FT-IR spectrum of monomer 1 (see Figure 5) showed the characteristic $\mathrm{Mo}=\mathrm{O}$ stretch at 940 and an imido stretch $\mathrm{Mo} \equiv \mathrm{N}$ at $947 \mathrm{~cm}^{-1}$.

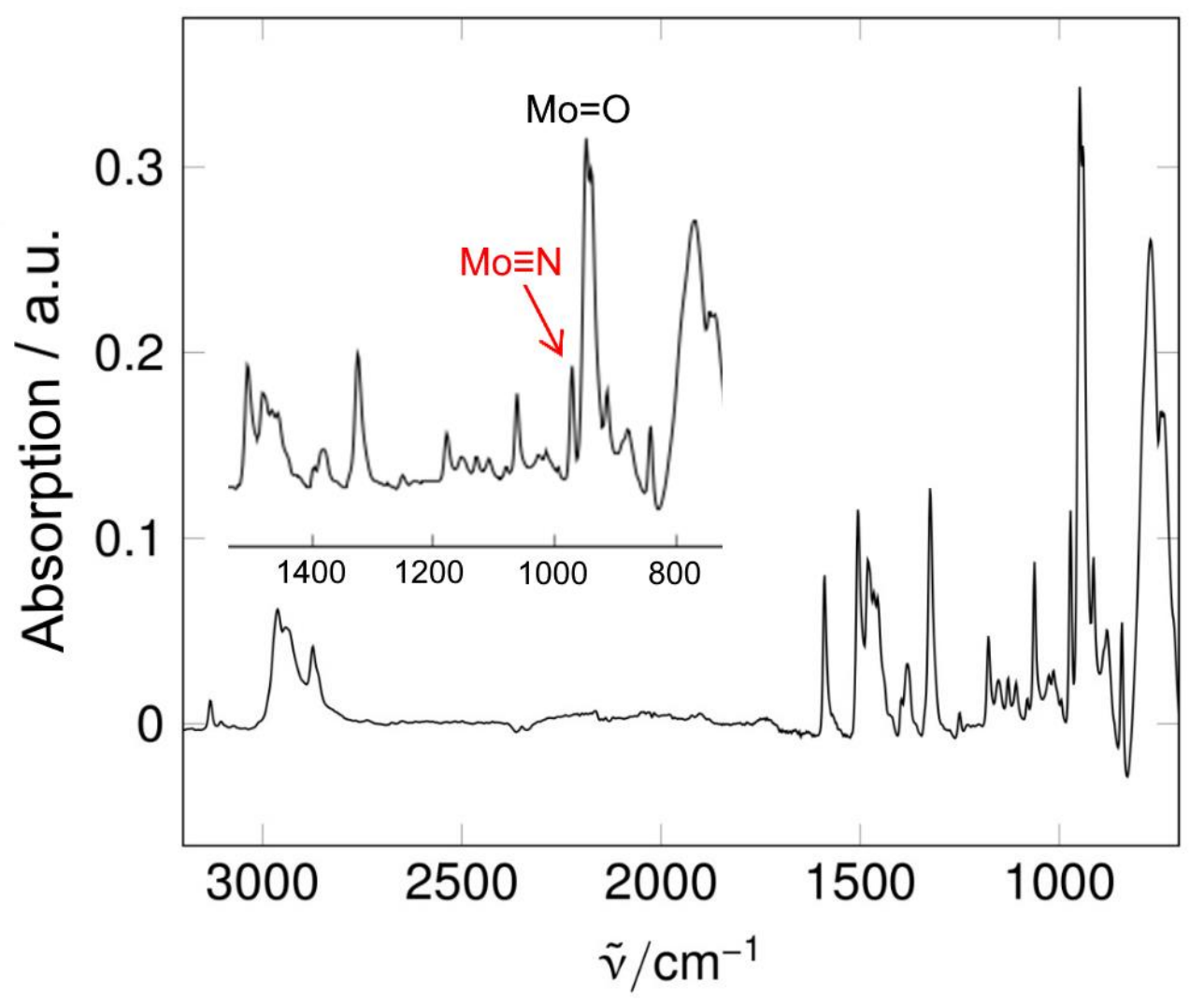

Figure 5. FTIR spectrum of monomer 1 using ATR technique showing the characteristic $\mathrm{Mo}=\mathrm{O}$ stretch at 940 and an imido stretch $\mathrm{Mo} \equiv \mathrm{N}$ at $947 \mathrm{~cm}^{-1}$.

When comparing monomer 1 with its corresponding PPy-1 co-polymer (Figure 5, black trace), the latter showed a shift in the position and a combination of these functional groups $(\mathrm{Mo}=\mathrm{O}$ and $\mathrm{Mo} \equiv \mathrm{N}$ ) between $950-916 \mathrm{~cm}^{-1}$. Figure 6 presents the reflectance FT-IR spectra of PPy-1 (black trace) and PPy only (red trace), showing a clear difference to PPy with the presence of $\mathrm{BF}_{4}^{-}$peak at $1070 \mathrm{~cm}^{-1}$ in both films, which is consistent with the literature. ${ }^{50}$ However, the strength of the 
$\mathrm{BF}_{4}^{-}$peak relative to the other vibrations is far weaker in PPy-1, showing that presence of the negatively charged POM reduces or eliminates the need to include anions to balance any positive charge on the PPy backbone. Indeed, at higher frequencies (Figure S3) the C-H stretching band for PPy-1 is far stronger than for PPy, consistent with substantial inclusion of $\mathrm{NBu}_{4}{ }^{+}$cations in the film to compensate for the presence of the self-doping POM monomers. Inclusion of $\mathrm{NBu}_{4}^{+}$ implies that the PPy-1 polymer carries a negative charge, and combined with the different potentials needed for electropolymerisation (vide supra) and the different behaviour to POM noncovalent inclusion films upon redox cycling (vide infra), shows that the POM monomers must be covalently connected as part of the backbone.

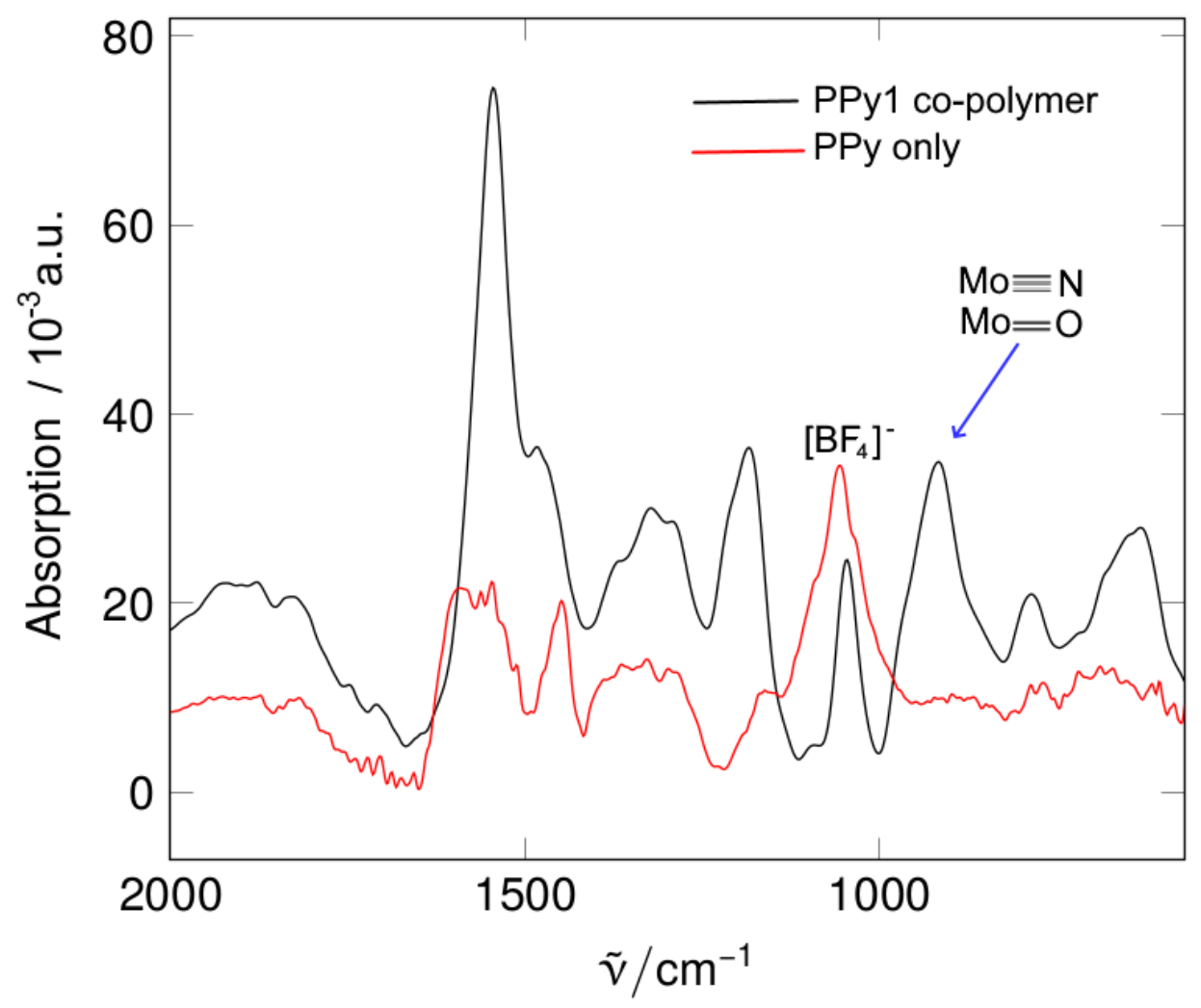

Figure 6. Reflectance FTIR spectrum of a Pt disc electrode coated with PPy only (red trace) and the PPy-1 co-polymer (black trace). 


\section{X-ray Photoelectron (XPS) and Energy-dispersive (EDX) X-ray Spectroscopies}

XPS was carried out on the FTO electrode coated with co-polymer films in the polypyrrole reduced (neutral) state. ${ }^{51}$ Figure 7 shows an XPS spectrum representative of the Mo3d core level for the PPy-1 and PPy-2 co-polymers, with the principal doublets obtained being the expected Mo(VI). Similar features were seen for different film thicknesses. The XPS derived surface elemental compositions in atomic \% (Table 1) are consistent with inclusion of a very significant proportion of POM-derivatised monomers in the polymeric films. Levels of molybdenum are approximately 10 times higher than those reported for $\left[\mathrm{Mo}_{6} \mathrm{O}_{19}\right]^{2-}$ inclusion films, ${ }^{38}$ and are supported by EDX results that also show around 5 to $6 \%$ Mo in the bulk of the films (Figure S4). Thus, covalent connection results in a far higher loading of POM than inclusion, and assuming inclusion of $c a .2$ tetrabutylammonium cations per POM in the polypyrrole reduced state we estimate that 15 to $25 \%$ of pyrrole units must carry a POM - enough for the POMs to make a substantial faradaic contribution to the capacitance of the films.

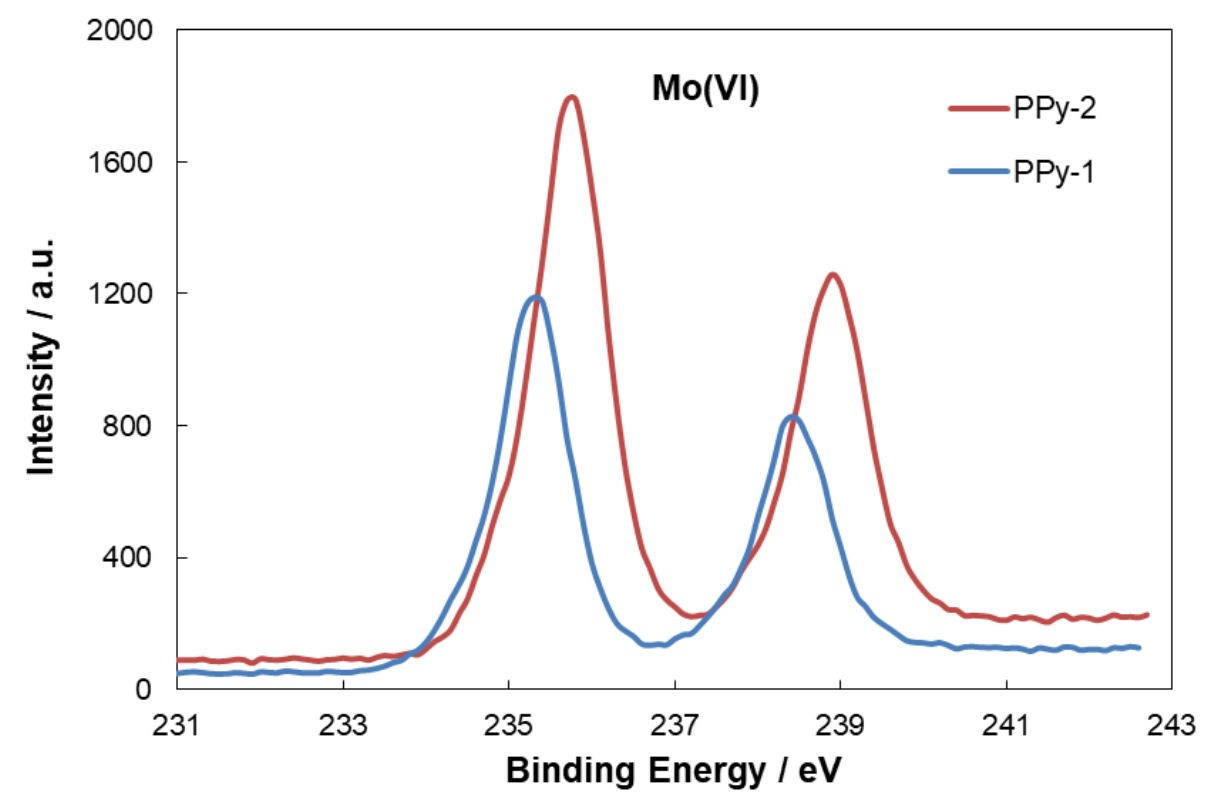

Figure 7. XPS spectrum of the Mo3d core levels for PPy-1 (blue) and PPy-2 co-polymers (red) of 20 deposition cycles film thickness. The data was calibrated with carbon signal at $288 \mathrm{eV}$. 
Table 1. XPS Surface Elemental Analysis.

\begin{tabular}{|c|c|c|c|c|c|c|c|}
\hline \multirow{3}{*}{$\begin{array}{l}\text { Material, } \\
\text { thickness }\end{array}$} & \multicolumn{6}{|c|}{ Elemental Abundance [atomic \%] } & \multirow{3}{*}{$\mathrm{S} 2 \mathrm{p}$} \\
\hline & C1s & F1s & Mo3d & N1s & $\mathrm{Na} 1 \mathrm{~s}$ & O1s & \\
\hline & & & & & & & \\
\hline PPy-1, 20 cycles & 69.16 & - & 6.96 & 5.23 & 0.34 & 17.25 & 1.05 \\
\hline PPy-2, 10 cycles & 75.76 & - & 4.70 & 4.63 & - & 14.00 & 0.92 \\
\hline PPy-2, 20 cycles & 75.49 & - & 5.00 & 5.16 & 0.01 & 14.17 & 0.17 \\
\hline PPy-2, 30 cycles & 72.34 & - & 5.90 & 4.19 & 0.00 & 17.27 & 0.31 \\
\hline PPy, 20 cycles & 73.36 & 0.38 & 0.22 & 8.93 & 0.25 & 14.44 & 2.43 \\
\hline
\end{tabular}

\section{Cyclic Voltammetry and Electrochemical Impedance Spectroscopy of the Films}

The change in polyoxometalate redox activity upon connection of monomers $\mathbf{1}$ and $\mathbf{2}$ into PPy-1 and PPy-2 was examined by cyclic voltammetry. The films (Figure 8a) show a well-defined reversible electrochemical behavior at slightly negatively shifted redox potentials $(c a .-0.55 \mathrm{~V})$ compared to the monomers (Figure S1 in the SI) and a fast redox process on the CV time scale is indicated by a small peak potential separation of $40 \mathrm{mV}$. This, and the linear dependence of the reduction current on scan rate (Figure 8d), confirms the presence of a surface confined POM species - after the $\mathrm{CV}$ is corrected for the slope resulting from resistance, the separation becomes $0 \mathrm{mV}$ (Figure S5 in the SI). To investigate film stability, consecutive cyclic voltammograms were carried out from $0 \mathrm{~V}$ to $-0.75 \mathrm{~V}$ on films of 10 deposition cycles. These show that on the $\mathrm{CV}$ timescale the resulting film of the PPy-1 co-polymer can undergo around 15 redox cycles (see Figure 8c) with only minimal changes, indicating the high stability of these films, due to the covalent linkage between the Lindqvist derivative and pyrrole units. This is clearly evident when 
comparing PPy-1 with an analogue made by the inclusion of $\left[\mathrm{Mo}_{6} \mathrm{O}_{19}\right]^{2-}$ in underivatised PPy, the latter showed a large decrease in the current intensity with shifting to less negative potential when moving from the redox cycle 1 to 2, see Figure 8b. Similar results indicating loss of POM were obtained for an analogue made by the inclusion of the arylimido-derivatised $\left[\mathrm{Mo}_{6} \mathrm{O}_{18} \mathrm{NArI}\right]^{2-}$ cluster in PPy (Figure S6 in the SI), showing that the improved stability of PPy-1 and PPy-2 is not simply a result of the bulky, appended organic group helping entrap the POM in the PPy matrix.
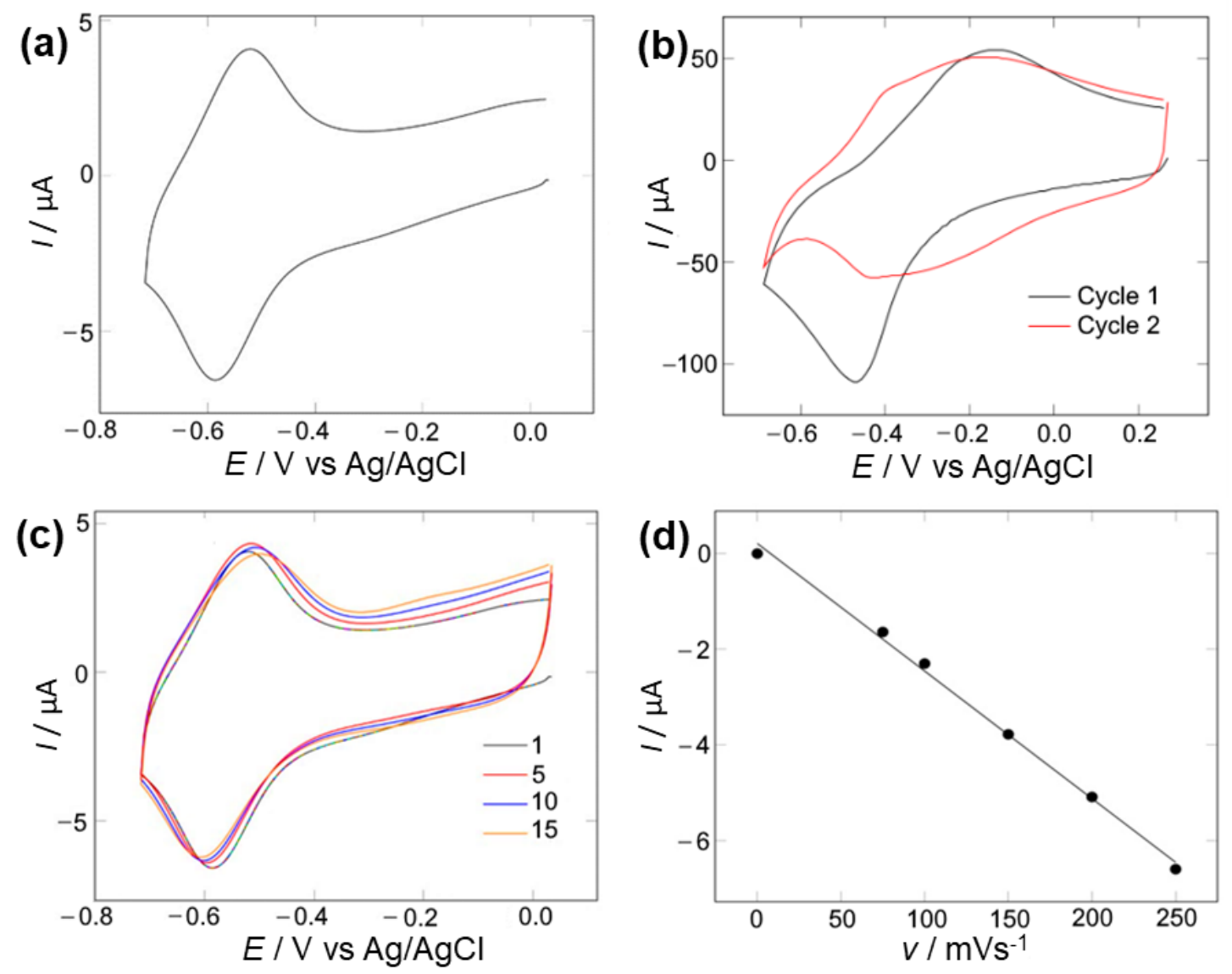

Figure 8. (a) CV showing the $\left\{\mathrm{Mo}_{6}\right\}$ redox wave in PPy-1. (b) CVs of an $\left\{\mathrm{Mo}_{6}\right\}$-PPy inclusion film showing the loss of POM after the first redox cycle. (c) Consecutive cyclic voltammograms of a PPy-1 film showing minimal changes from redox cycle 1 to 15 . (d) A plot of current peak $I_{\mathrm{pc}}$ vs scan rate $(v)$ for reduction of PPy-1 film. Conditions: electrolyte $0.1 \mathrm{M} \mathrm{NBu}_{4} \mathrm{BF}_{4}$ in $\mathrm{MeCN}$, scan rate $100 \mathrm{mV} / \mathrm{s}$, working electrode $0.07 \mathrm{~cm}^{2} \mathrm{GC}, \mathrm{Ag} / \mathrm{AgCl}$ as reference electrode. 
Full range cyclic voltammograms of PPy-1 and PPy-2 are shown in Figure 9. Both POM and PPy processes are clearly visible, consistent with the high level of POM functionalisation determined by XPS and EDX. Integrating the oxidation wave of the PPy (from -0.2 to $0.6 \mathrm{~V}$ ) and the reduction wave of $\left\{\mathrm{Mo}_{6}\right\}$ from $(-0.2$ to $-0.8 \mathrm{~V})$ indicates that around 20 to $30 \%$ of pyrrole monomers are derivatised with a POM. This is slightly higher than suggested by XPS, but represents a good agreement given the considerable uncertainties involved in integrating a cyclic voltammogram - such as choice of baseline and the contribution of double layer capacitance.

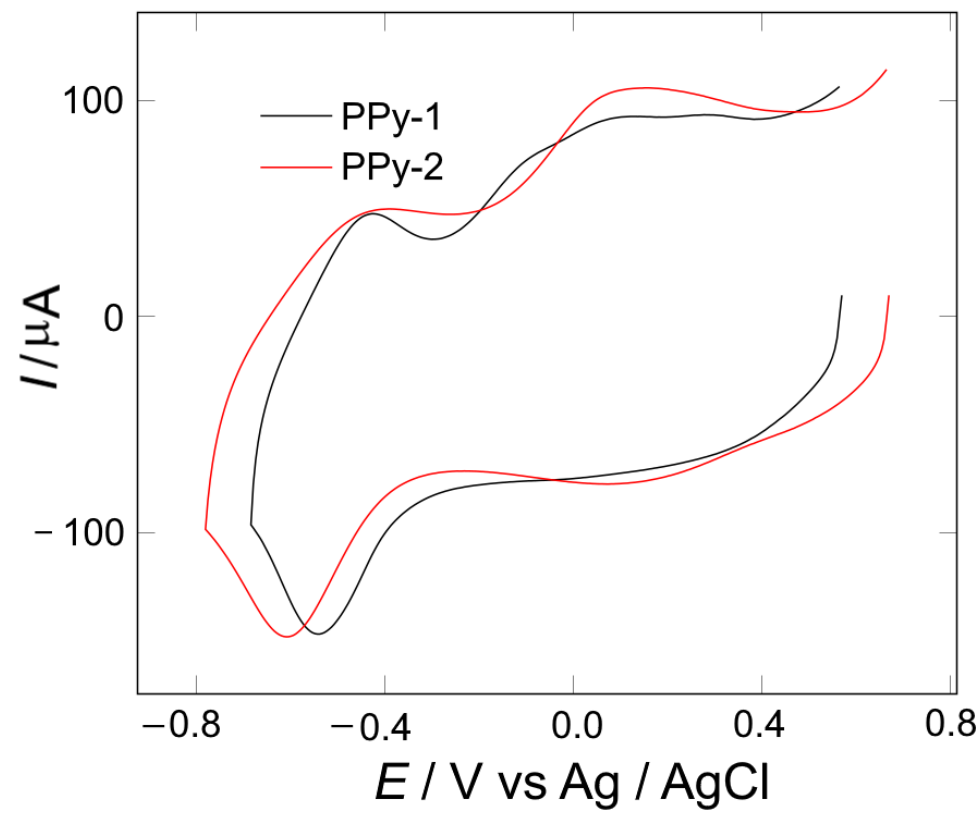

Figure 9. CVs of PPy-1 (black trace) and PPy-2 (red trace) of 10 cycles film thickness on FTO electrode in $0.1 \mathrm{M} \mathrm{NBu}_{4} \mathrm{BF}_{4} / \mathrm{MeCN}$ at $25^{\circ} \mathrm{C}$ vs $\mathrm{Ag} / \mathrm{AgCl}$ at scan rate $250 \mathrm{mV} / \mathrm{s}$.

Electrochemical impedance spectroscopy (EIS) was performed in the conductive, capacitive voltage region of the polypyrroles to obtain comprehensive information about the properties of capacitors based on the PPy component, and results are shown in Figure 10. Nyquist plots include three parts, a semicircle at high frequency region corresponds to the charge transfer resistance, a transition region possibly associated with Warburg impedance (W) within the film, and the 
straight-line (C) part at low frequency corresponding to the ion (electrolyte) charging during the charge/discharge process. The semi-circles of PPy-1 and PPy-2 in the high frequency region are much smaller than for the PPy electrode, indicating a much lower apparent charge transfer resistance $\left(\mathrm{R}_{\mathrm{ct}}\right)$. As the POMs cannot be participating in Faradaic reactions at the potential used for the measurement $(+0.6 \mathrm{~V})$, the likely explanation for this is a more open structure with a higher surface area for charge transfer between film and electrolyte. ${ }^{52,53}$ In the low-frequency domains, both PPy-1 and PPy-2 show similar behaviour.
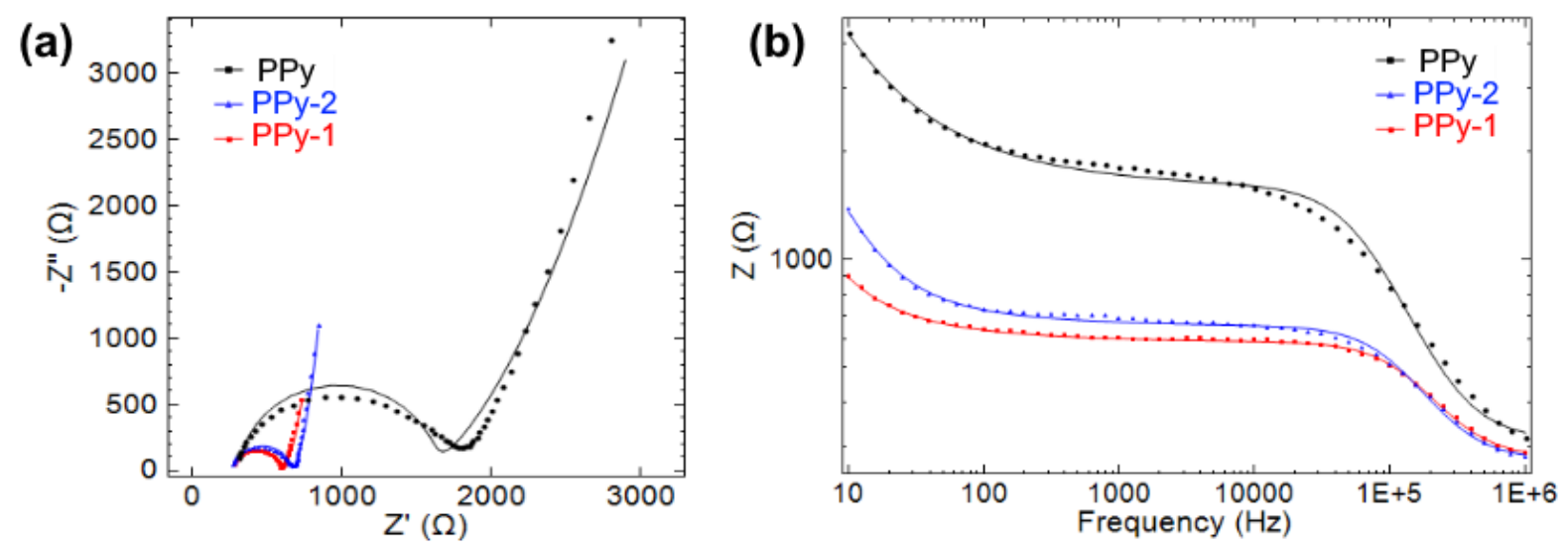

(c)

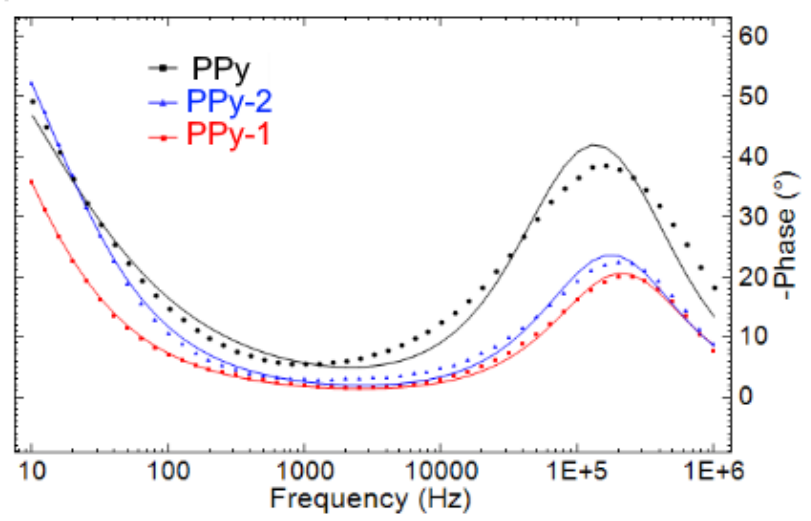

(d)
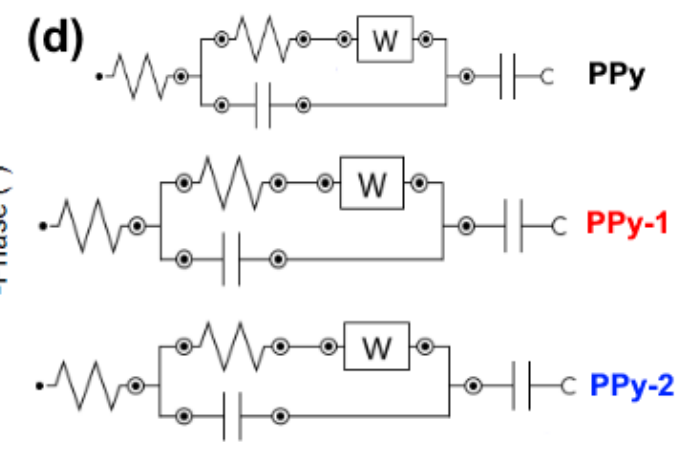

Figure 10. (a) Nyquist plot, (b) Bode plot, (c) Phase plot and (d) Electrochemical circuit fit of 10 cycles-deposited films of PPy at 0.9 V, and PPy-1 and PPy-2 at $0.6 \mathrm{~V}$ vs $\mathrm{Ag} / \mathrm{Ag}^{+}$with $1 \mathrm{~mA}$ current. Points are experimental data and lines are fits. 
The Bode and Phase angle plots (Figure $10(\mathrm{~b} / \mathrm{c})$ show that at low frequencies $(10 \mathrm{~Hz})$, the phase angle of PPy-2 is $53^{\circ}$, higher than for PPy $\left(50^{\circ}\right)$ or PPy- $1\left(36^{\circ}\right)$. This indicates that PPy-2 has the most ideal capacitive performance. At higher frequencies, the phase angles of PPy-1 and PPy-2 fall to $19^{\circ}$ and $22^{\circ}$ respectively. This is (in part) due to Warburg impedance and arises from the porous structure of the film. The difference to PPy may be linked to inclusion of $\mathrm{NBu}_{4}{ }^{+}$cations, rather than $\mathrm{BF}_{4}^{-}$anions in the film $-\mathrm{NBu}_{4}{ }^{+}$is large and upon oxidation there may be processes ejecting it from the film, as well as taking in the smaller $\mathrm{BF}_{4}{ }^{-}$anions. Figure 10 (d) shows the electrochemical circuit fit where $R_{\mathrm{S}}$ is the solution resistance. $R_{1}$ and $C_{1}$ are the resistance and capacitance of the double layer capacitor and $C_{2}$ is capacitance of the pseudocapacitor, resulting from the film.

Table 2. Electrode behavior (PPy, PPy-1 and PPy-2) calculated from the electrochemical circuit fit of the experimental EIS data.

\begin{tabular}{ccclll}
\hline Sample & $R_{\mathrm{S}}$ & $R_{1}$ & $C_{1}$ & $C_{2}$ & $Y_{0}{ }^{a}$ \\
& {$[\Omega]$} & {$[\Omega]$} & {$[\mathrm{F}]$} & {$[\mathrm{F}]$} & {$\left[\mu \mathrm{S} \mathrm{s}^{0.5}\right]$} \\
\hline PPy & 316 & 1280 & $2.06 \times 10^{-9}$ & $8.85 \times 10^{-6}$ & 68.6 \\
PPy-1 & 282 & 308 & $3.55 \times 10^{-9}$ & $41.6 \times 10^{-6}$ & 659 \\
${ }^{a}$ RPy-2 & 278 & 375 & $3.68 \times 10^{-9}$ & $17.9 \times 10^{-6}$ & 486 \\
\cline { 3 - 4 } & & & &
\end{tabular}

\section{Specific Capacitance and Charge-Discharge Stability}

The specific charge $\left(\mathrm{C}_{\text {charge }}\right)$ and discharge $\left(\mathrm{C}_{\text {discharge }}\right)$ capacitances associated with the polypyrrole and $\left\{\mathrm{Mo}_{6}\right\}$ anions over a potential range of 0.7 to $-0.8 \mathrm{~V}$, were calculated by 
integrating the current density of the CV curve in the oxidation wave for polypyrrole and in the reduction wave for the $\left\{\mathrm{Mo}_{6}\right\}$ anions, respectively (Figure 9). This energy storage property has been calculated, and tabulated as capacitance $\left(\mathrm{F} \mathrm{g} \mathrm{g}^{-1}\right)$, because most of the storage occurs in the polypyrrole which is considered to be a pseudocapacitor. There is, however, considerable current discussion of systems that lie at the boundary between batteries and pseudocapacitors, ${ }^{19,54-56}$ and CVs showing clear polyoxometalate peaks for PPy-1 and PPy-2 indicate that their energy storage mechanism is not purely pseudocapacitive - they have some battery like character. Accordingly, below we also provide capacities in mAh for these two materials.

Table 3. Specific capacitance of PPy, PPy-1, and PPy-2 obtained from CV at $250 \mathrm{mV} \mathrm{s}^{-1}$.

\begin{tabular}{llll}
\hline \multicolumn{5}{l}{ Specific Capacitance $\left[\mathrm{F} \mathrm{g}^{-1}\right]$} & \\
& Polypyrrole & & \\
& & & \\
Sample & & POM $^{\text {red }}$ & Total \\
PPy & 11.5 & - & 11.5 \\
PPy-1 & 22 & 11.5 & 33.5 \\
PPy-2 & 34 & 19 & 53 \\
\hline
\end{tabular}

Compared to un-derivatized polypyrrole (PPy) measured under the same conditions, films with covalently-connected $\left\{\mathrm{Mo}_{6}\right\}$ anions show a significant increase in the specific capacitance of the polypyrrole - to $22 \mathrm{~F} \mathrm{~g}^{-1}$ for PPy-1 and $34 \mathrm{~F} \mathrm{~g}^{-1}$ for PPy-2, see Table 3. This corresponds to a specific capacitance increase of ca. 2× vs PPy for PPy-1, and $3 \times$ for PPy-2, roughly in line with that seen for non-covalent inclusion of $\left[\mathrm{Mo}_{6} \mathrm{O}_{19}\right]^{2-}$ in PPy $(2 \times) .{ }^{38}$ However, the large loading of polyoxometalate in these films means that it also contributes a significant pseudo-capacitance. 
This was assessed in the same way as the PPy contribution, revealing that the POM contributes around $50 \%$ of the capacitance of the polypyrrole film, to give totals of $33.5 \mathrm{~F} \mathrm{~g}^{-1}$ for PPy-1 and $52 \mathrm{~F} \mathrm{~g}^{-1}$ for PPy-2 and thus an enhancement $v$ s PPy of 3 to $5 \times$. Considering the battery-like character of these systems, this translates to capacities of ca. $14 \mathrm{mAhg}^{-1}$ and $22 \mathrm{mAhg}^{-1}$, respectively. The overall POM contribution to charge storage is approximately consistent with the ratio of POMs to pyrrole units estimated by XPS, considering that each POM stores one electron on reduction, and each pyrrole 0.33 positive charges on oxidation. Overall, the results show that the modification of PPy with hexamolybdate $\left\{\mathrm{Mo}_{6}\right\}$ anions via covalent linkage gives access to composites with enhanced capacitive charge storage that can be ascribed both to steric bulk which improves the structure (surface area/porosity) of the film, and a direct faradaic contribution from the POM electron acceptor.

Galvanostatic charge-discharge (GCD) measurements (Figure 11) were also used to evaluate the specific capacitance and electrochemical stability of PPy, PPy-1 and PPy-2 over 1200 cycles. The specific capacitance was calculated according to the following equation:

$$
C s=\frac{I \Delta t}{A \Delta E}
$$

Where $I$ is the maximum constant current (A), $t$ is time (s), $E$ is the potential $(\mathrm{V})$ during the chargedischarge process, and $A$ is the area of the electrode. The GCD curves are almost symmetrical, indicating good capacitive behaviour. Notably, the curves for PPy-1 and PPy-2 extend to negative voltages, consistent with involvement of the POM in the process, and the time per charge/discharge cycle is shorter than for PPy, at around 21 seconds vs 36 seconds - indicating better charge transport in the POM derivatised films. The specific capacitances (Table 4) follow the same trend as those obtained by cyclic voltammetry, with PPy-1 and PPy-2 showing excellent agreement with 
the total POM + polypyrrole capacitance calculated from the CV. Calculation of capacity produces values of ca. $11 \mathrm{mAh} \mathrm{g}^{-1}$ for both materials, the value for PPy-2 dropping substantially compared to that assessed by $\mathrm{CV}$ because of the smaller voltage range observed in the GCD curves.
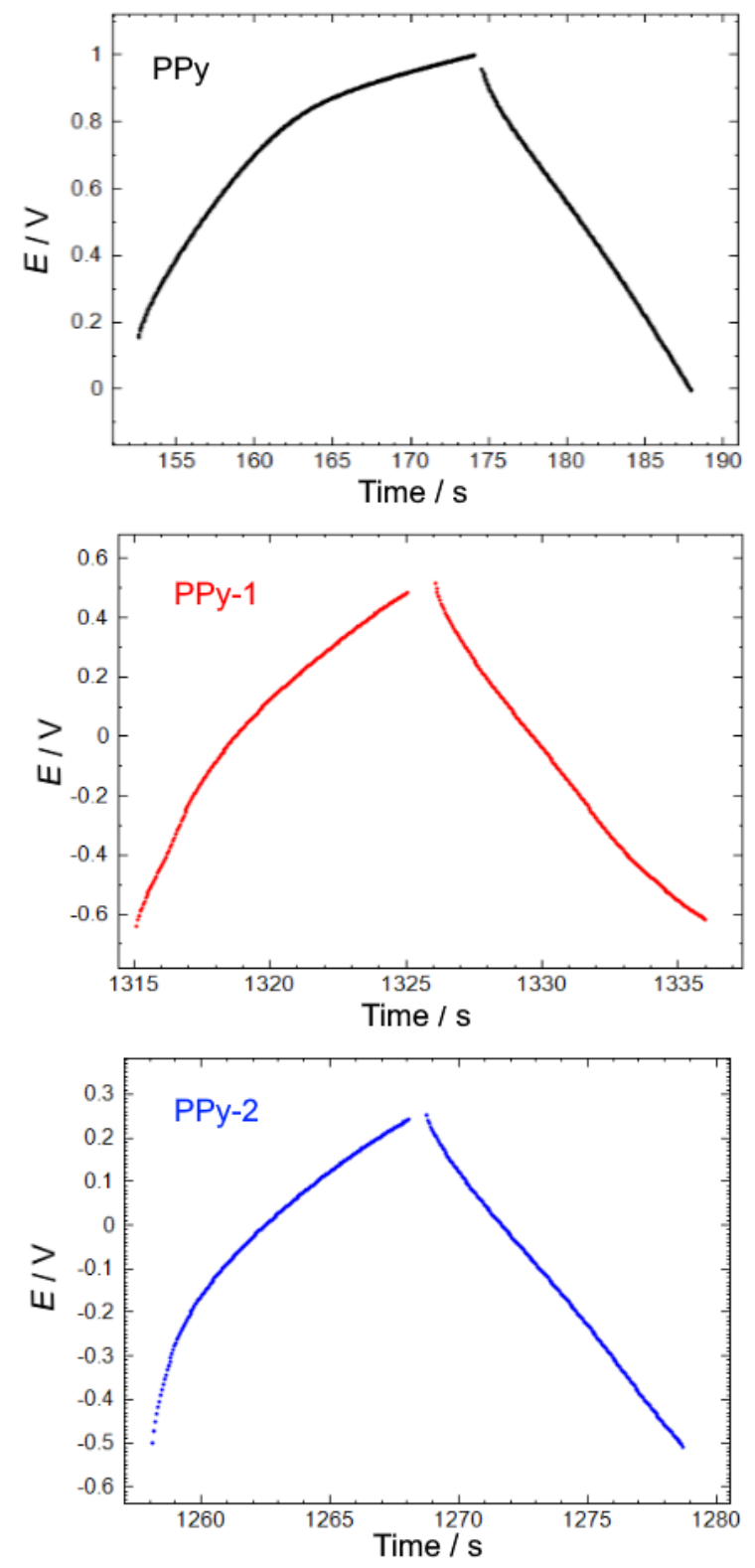

Figure 11. Galvanostatic charge-discharge curves for 10 cycle PPy, PPy-1 and PPy-2 films on GC electrodes. Electrolyte: $0.1 \mathrm{M} \mathrm{NBu}_{4} \mathrm{BF}_{4} / \mathrm{MeCN}$ at $25^{\circ} \mathrm{C}$ vs $\mathrm{Ag}$ wire reference. 
Table 4. Specific capacitance of PPy, PPy-1, and PPy-2 obtained from GCD analysis.

\begin{tabular}{ll}
\hline Sample & $\begin{array}{l}\text { Specific Capacitance } \\
{\left[\mathrm{F} \mathrm{g}^{-1}\right]}\end{array}$ \\
\hline PPy & 19 \\
PPy-1 & 35 \\
PPy-2 & 54 \\
\hline
\end{tabular}
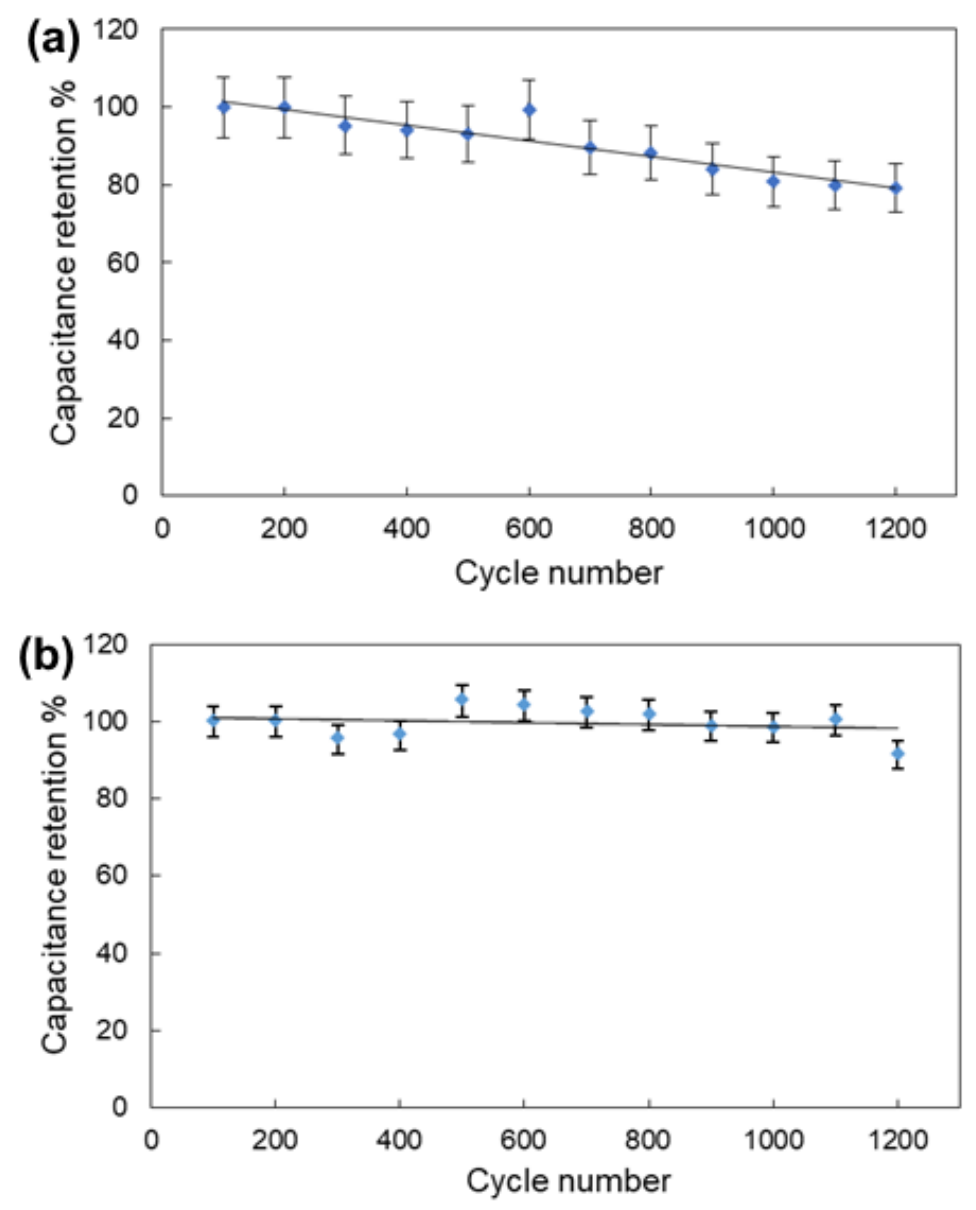

Figure 12. Capacitance retention \% of (a) PPy-1 and (b) PPy-2 of 10 cycles-deposited film thickness on GC electrodes for the first 1200 cycles. Electrolyte: $0.1 \mathrm{M} \mathrm{NBu} 4 \mathrm{BF}_{4} / \mathrm{MeCN}$ at $25^{\circ} \mathrm{C}$ vs Ag wire reference. 
Interestingly, PPy-2 shows better multi-cycle stability compared with PPy-1. Figure 12 shows the capacitance retention of both co-polymers where PPy-1 exhibits $81 \%$ and PPy-2 95\% capacitance retention over 1200 cycles. Thus, while the multi-cycle stability of PPy-1 is comparable to that shown for non-covalent inclusion of $\left[\mathrm{Mo}_{6} \mathrm{O}_{19}\right]^{2-38}$, PPy-2 demonstrates the potential of covalent linkage to improve the stability of POM-polymer composite systems. The improved performance of PPy-2 compared to PPy-1 in both stability and specific capacitance is consistent with the with the longer spacer between pyrrole-N and POM forcing larger ion channels, increasing active surface area and reducing disruption of the film by ion migration.

\section{Conclusions}

Polypyrrole supercapacitors with covalently linked Lindqvist polyoxometalates were successfully prepared by electropolymerisation. These films are the first covalent POM-PPy hybrids, and as the first demonstration of electropolymerisation of a POM-derivatised monomer they open new possibilities for construction of POM hybrid materials. The covalent linkage gives access to far higher loadings of POM than obtained in non-covalent inclusion films, prevents loss of POM in early reduction cycles, and increasing its length increases both the specific capacitance and stability of the film to cycling - such that $95 \%$ capacitance retention over 1200 cycles is achieved for the longer diphenylacetylene spacer. Crucially, the POM enhances specific capacitance both by modifying the polypyrrole itself, with reduced charge transfer resistance implying that a more open structure results from the steric bulk of the POMs, and by a direct faradaic contribution through the POM redox process. Future work will focus on optimising the loading of the POM for the best specific capacitance and expand the approach to POMs capable of storing multiple electrons. 


\section{ASSOCIATED CONTENT}

Supporting Information. Additional cyclic voltammograms of monomers and electropolymer films, photographs of coated electrodes, additional FTIR data and EDX spectra.

Data Sharing Statement. In addition to the supplementary information, data can be accessed by contacting the corresponding author.

\section{AUTHOR INFORMATION}

\section{Corresponding Author}

* John Fielden: Tel:+44(0)1603 593 137, e-mail:*john.fielden@uea.ac.uk

* Ahmed Al-Yasari: e-mail: a.alyasari@uokerbala.edu.iq

\section{Author Contributions}

The manuscript was written through contributions of all authors. All authors have given approval to the final version of the manuscript.

\section{Funding Sources}

See acknowledgement.

\section{ACKNOWLEDGMENT}

We thank Professor Chris Pickett and Dr Saad Ibrahim of the University of East Anglia for helpful discussions on electropolymerisation, Dr Michael Ward, Dr Benjamin Johnson and Dr 
Kellye Curtis of LENNF (University of Leeds) for electron microscopy and XPS measurements and Mr. Bertrand Leze of the University of East Anglia for electron microscopy measurements. AAY thanks the Iraqi Government for financial support via the Ministry of Higher Education and Scientific Research (MOHER) - University of Kerbala for a postdoctoral fellowship, and SAA thanks Princess Nourah bint Abdulrahman University for a PhD scholarship. This work was also supported by EU FP7 (Marie Curie IOF POMHYDCAT contract 254339 to JF), EPSRC (EP/M00452X/1), and the University of East Anglia.

\author{
ABBREVIATIONS \\ PPy, polypyrrole; POM, polyoxometalate; TEM, transmission electron microscopy; SEM, \\ scanning electron microscopy; $\mathrm{CP}$, conducting polymer; GC, glassy carbon; EIS, electrochemical \\ impedance spectroscopy; GCD, galvanostatic charge-discharge; EQCM, electrochemical quartz \\ crystal microbalance; FTIR, Fourier-transform infra-red; XPS, X-ray photoelectron \\ spectroscopy; EDX, energy dispersive X-ray spectroscopy; FTO, Fluorine Tin Oxide.
}

\title{
REFERENCES
}

1. Long, D. L.; Burkholder, E.; Cronin, L. Polyoxometalate clusters, nanostructures and materials: From self assembly to designer materials and devices. Chem. Soc. Rev. 2007, 36, $105-121$.

2. Long, D. L.; Cronin, L. Pushing the frontiers in polyoxometalate and metal oxide cluster science. Dalton Trans. 2012, 41, 9815- 9816.

3. Buru, C. T.; Farha, O. K. Strategies for incorporating catalytically active polyoxometalates in metal-organic frameworks for organic transformations. ACS Appl. Mater. Interfaces 2020, 12, 5345- 5360. 
4. Wang, S. S.; Yang, G. Y. Recent advances in polyoxometalate-catalyzed reactions. Chem. Rev. 2015, 115, 4893-4962.

5. Sumliner, J. M.; Lv, H.; Fielden, J.; Geletii, Y. V.; Hill, C. L. Polyoxometalate multi-electrontransfer catalytic systems for water splitting. Eur. J. Inorg. Chem. 2014, 2014, 635- 644.

6. Clemente-Juan, J. M.; Coronado, E.; Gaita-Ariñoa, A. Magnetic polyoxometalates: from molecular magnetism to molecular spintronics and quantum computing. Chem. Soc. Rev. 2012, 41, 7464- 7478.

7. Boskovic, C. Rare earth polyoxometalates. Acc. Chem. Res. 2017, 50, 2205- 2214.

8. Liu, S.; Kurth, D. G.; Möhwald, H.; Volkmer, D. A thin-film electrochromic device based on a polyoxometalate cluster. Adv. Mater. 2002, 14, 225-228.

9. Al-Yasari, A.; Van Steerteghem, N.; Kearns, H.; El Moll, H.; Faulds, K.; Wright, J. A.; Brunschwig, B. S.; Clays, K.; Fielden, J. Organoimido-Polyoxometalate nonlinear optical chromophores: a structural, spectroscopic, and computational study. Inorg. Chem. 2017, 56, 10181-10194.

10. El Moll, H.; Black, F. A.; Wood, C. J.; Al-Yasari, A.; Reddy Marri, A.; Sazanovich, I. V.; Gibson, E. A.; Fielden, J. Increasing p-type dye sensitised solar cell photovoltages using polyoxometalates. Phys. Chem. Chem. Phys. 2017, 19, 18831- 18835.

11. Wang, H.; Hamanaka, S.; Nishimoto, Y.; Irle, S.; Yokoyama, T.; Yoshikawa, H.; Awaga, K. In Operando X-ray absorption fine structure studies of polyoxometalate molecular cluster batteries: polyoxometalates as electron sponges. J. Am. Chem. Soc. 2012, 134, 4918- 4924. 
12. Proust, A.; Matt, B.; Villanneau, R.; Guillemot, G.; Gouzerh, P.; Izzet, G. Functionalization and post-functionalization: a step towards polyoxometalate-based materials. Chem. Soc. Rev. 2012, 41, 7605-7622.

13. Anyushin, A. V.; Kondinski, A.; Parac-Vogt, T. N. Hybrid polyoxometalates as postfunctionalization platforms: from fundamentals to emerging applications. Chem. Soc. Rev. 2020, 49, 382-432.

14. Dolbecq, A.; Dumas, E.; Mayer, C. R; Mialane, P. Hybrid organic-inorganic polyoxometalate compounds: from structural diversity to applications. Chem. Rev. 2010, 110, 6009- 6048.

15. Kibler, A. J.; Newton, G. N. Tuning the electronic structure of organic-inorganic hybrid polyoxometalates: The crucial role of the covalent linkage. Polyhedron 2018, 154, 1-20.

16. Ammam, M. Polyoxometalates: formation, structures, principal properties, main deposition methods and application in sensing. J. Mater. Chem. A 2013, 1, 6291- 6312.

17. Ji, Y.; Huang, L.; Hu, J.; Streb, C.; Song, Y.-F. Polyoxometalate-functionalized nanocarbon materials for energy conversion, energy storage and sensor systems. Energy Environ. Sci. 2015, $8,776-789$.

18. Li, Q.; Zhang, L.; Dai, J.; Tang, H.; Li, Q.; Xue, H.; Pang, H. Polyoxometalate-based materials for advanced electrochemical energy conversion and storage. Chem. Eng. J. 2018, 351, 441461.

19. Dubal, D. P.; Ayyad, O.; Ruiz, V.; Gómez-Romero, P. Hybrid energy storage: the merging of battery and supercapacitor chemistries. Chem. Soc. Rev. 2015, 44, 1777- 1790. 
20. Li, X.; Zhou, K. F.; Tong, Z. B.; Yang, X. Y.; Chen, C. Y.; Shang, X. H.; Sha, J. Q. Heightened integration of pom-based metal-organic frameworks with functionalized single-walled carbon nanotubes for superior energy storage. Chem. - An Asian J. 2019, 14, 3424-3430.

21. Tsunashima, R.; Iwamoto, Y.; Baba, Y.; Kato, C.; Ichihashi, K.; Nishihara, S.; Inoue, K.; Ishiguro, K.; Song, Y. F.; Akutagawa, T. Electrical network of single-crystalline metal oxide nanoclusters wired by $\pi$-molecules. Angew. Chemie - Int. Ed. 2014, 53, 11228- 11231.

22. Dubal, D. P.; Lee, S. H.; Kim, J. G.; Kim, W. B.; Lokhande, C. D. Porous polypyrrole clusters prepared by electropolymerization for a high performance supercapacitor. J. Mater. Chem. 2012, 22, 3044- 3052 .

23. Ghosh, S.; Maiyalagan, T.; Basu, R. N. Nanostructured conducting polymers for energy applications: towards a sustainable platform. Nanoscale 2016, 8, 6921- 6947.

24. Fu, L.; Qu, Q.; Holze, R.; Kondratiev, V. V.; Wu, Y. Composites of metal oxides and intrinsically conducting polymers as supercapacitor electrode materials: the best of both worlds. J. Mater. Chem. A 2019, 7, 14937- 14970.

25. Holze, R. In Metal oxides in supercapacitors; 2017, 219- 245.

26. Yuan, X.; Dragoe, D.; Beaunier, P.; Uribe, D. B.; Ramos, L.; Méndez-Medrano, M. G.; Remita, H. Polypyrrole nanostructures modified with mono- and bimetallic nanoparticles for photocatalytic $\mathrm{H}_{2}$ generation. J. Mater. Chem. A 2020, 8, 268- 277.

27. Yang, J.; Liu, Y.; Liu, S.; Li, L.; Zhang, C.; Liu, T. Conducting polymer composites: material synthesis and applications in electrochemical capacitive energy storage. Mater. Chem. Front. 2017, 1, 251- 268. 
28. D. P. Dubal, B. Ballesteros, A. A. Mohite, P. Gómez-Romero, Functionalization of polypyrrole nanopipes with redox-active polyoxometalates for high energy density supercapacitors. ChemSusChem 2017, 10, 731- 737.

29. Chang, Z.; Sang, X.; Song, Y.; Sun, X.; Liu, X. X. Immobilization of phosphotungstate through doping in polypyrrole for supercapacitors. Dalton Trans. 2019, 48, 6812- 6816.

30. Suppes, G. M.; Cameron, C. G.; Freund, M. S. Polypyrrole/Phosphomolybdic acid mid poly (3, 4-ethylenedioxythiophene)/phosphotungstic acid asymmetric supercapacitor. J. Electrochem. Soc. 2010, 157, 1030.

31. Cheng, S.; Fernández-Otero, T.; Coronado, E.; Gómez-García, C. J.; Martínez-Ferrero, E.; Giménez-Saiz, C. Hybrid material polypyrrole/[ $\left.\mathrm{SiCr}\left(\mathrm{H}_{2} \mathrm{O}\right) \mathrm{W}_{11} \mathrm{O}_{39}\right]^{5-}$ : electrogeneration, properties, and stability under cycling. J. Phys. Chem. B 2002, 106, 7585- 7591.

32. Otero, T. F.; Cheng, S. A.; Alonso, D.; Huerta, F. Hybrid materials polypyrrole/ $/ \mathrm{PW}_{12} \mathrm{O}_{40}{ }^{3-} .1$. Electrochemical synthesis, kinetics and specific charges. J. Phys. Chem. B 2000, 104, 1052810527.

33. Sung, H.; So, H.; kie Paik, W. Polypyrrole doped with heteropolytungstate anions. Electrochim. Acta 1994, 39, 645- 650.

34. Herrmann, S.; Ritchie, C.; Streb, C. Polyoxometalate - conductive polymer composites for energy conversion, energy storage and nanostructured sensors. Dalton Trans. 2015, 44, 70927104.

35. Zhai, L.; Li, H. Polyoxometalate-Polymer hybrid materials as proton exchange membranes for fuel cell applications. Molecules 2019, 24, 3425- 3445. 
36. Lu, M.; Xie B.; Kang, J.; Chen, F.-C.; Yang, Peng, Z. Synthesis of main-chain polyoxometalate-containing hybrid polymers and their applications in photovoltaic cells. Chem. Mater. 2005, 17, 402- 408.

37. Qi, W.; Wu, L. Polyoxometalate/polymer hybrid materials: fabrication and properties. Polym. Int. 2009, 58, 1217- 1225.

38. Herrmann, S.; Aydemir, N.; Nägele, F.; Fantauzzi, D.; Jacob, T.; Travas-Sejdic, J.; Streb, C. Enhanced capacitive energy storage in polyoxometalate-doped polypyrrole. Adv. Funct. Mater. 2017, 27, 1700881-1700889.

39. Ibrahim, S. K. New electrochemical reactions of some metallo-sulphur compounds including the activation of NO and NHR ligands at Mo-S centres, PhD Thesis, University of Sussex, 1992.

40. Al-Yasari, A.; Van Steerteghem, N.; El Moll, H.; Clays, K.; Fielden, J. Donor-acceptor organo-imido polyoxometalates: high transparency, high activity redox-active NLO chromophores. Dalton Trans. 2016, 45, 2818- 2822.

41. Sadki, S.; Schottland, P.; Brodie, N.; Sabouraud, G. The mechanisms of pyrrole electropolymerization. Chem. Soc. Rev. 2000, 29, 283- 293.

42. Thompson, B. C.; Abboud, K. A.; Reynolds, J. R.; Nakatani, K.; Audebert, P. Electrochromic conjugated N-salicylidene-aniline (anil) functionalized pyrrole and 2,5-dithienylpyrrole-based polymers. New J. Chem. 2005, 29, 1128- 1134. 
43. Reynolds, J. R.; Poropatic, P. A.; Toyooka, R. L. Electrochemical copolymerization of pyrrole with N-substituted pyrroles. Effect of composition on electrical conductivity. Macromolecules 1987, 20, 958- 961.

44. Wallace, G. G.; Teasdale, P. R.; Spinks, G. M.; Kane-Maguire, L. A. P. Conductive electroactive polymers: intelligent materials systems, Boca Raton:CRC Press, 2009.

45. Heinze, J.; Frontana-Uribe, B. A.; Ludwigs, S. Electrochemistry of conducting polymerspersistent models and new concepts. Chem. Rev. 2010, 110, 4724- 4771.

46. Rosenthal, M. V.; Skotheim, T. A.; Melo, A.; Florit, M. I.; Salmon, M. Electrochemical synthesis of polypyrrole/poly-N-(p-nitrophenyl)pyrrole co-polymer. J. Electroanal. Chem. Interf. Electrochem. 1985, 185, 297- 303.

47. Kumar, S.; Krishnakanth, S.; Mathew, J.; Pomerantz, Z.; Lellouche, J. P.; Ghosh, S. Effect of $\mathrm{N}-\alpha$ substitution on the electropolymerization of n-substituted pyrroles: structure-reactivity relationship studies. J. Phys. Chem. C 2014, 118, 2570- 2579.

48. Kupila, E. L.; Kankare, J. Influence of electrode pretreatment, counter anions and additives on the electropolymerization of pyrrole in aqueous solutions. Synth. Met. 1995, 74, 241- 249.

49. Abaci, U.; Guney, H. Y.; Kadiroglu, U. Morphological and electrochemical properties of PPy, PAni bilayer films and enhanced stability of their electrochromic devices (PPy/PAni-PEDOT, PAni/PPy-PEDOT). Electrochim. Acta 2013, 96, 214.

50. Le Gall, T.; Passes, M. S.; Ibrahim, S. K.; Morlat-Therias, S.; Sudbrake, C.; Fairhurst, S. A.; Arlete Queiros, M.; Pickett, C. J. Synthesis of N-derivatised pyrroles: precursors to highly functionalised electropolymers. J. Chem. Soc. - Perkin Trans. 1 1999, 1657- 1664. 
51. Reiners, G. Corrosion Books: Surface Science - An introduction. by: K. Oura, V.G. Lifshits, A. A. Saranin, A. V. Zotov, M. Katayama. Mater. Corros. 2004, 55, 136-137.

52. Raudsepp, T.; Marandi, M.; Tamm, T.; Sammelselg, V.; Tamm, J. Study of the factors determining the mobility of ions in the polypyrrole films doped with aromatic sulfonate anions. Electrochim. Acta 2008, 53, 3828- 3835.

53. Ingram, M. D.; Staesche, H.; Ryder, K. S. 'Ladder-doped' polypyrrole: a possible electrode material for inclusion in electrochemical supercapacitors. J. Power Sources 2004, 129, 107112.

54. Simon, P.; Gogotsi, Y.; Dunn, B. Where do batteries end and supercapacitors begin? Science 2014, 343, 1210-1211.

55. Zuo, W.; Li, R.; Zhou, C.; Li, Y.; Xia, J.; Liu, J. Ba. Battery-Supercapacitor Hybrid Devices: Recent Progress and Future Prospects. Adv. Sci. 2017, 4, 1600539.

56. Simon, P.; Gogotsi, Y. Perspectives for electrochemical capacitors and related devices. Nature Mater. 2020, 19, 1151-1163. 